\title{
$\alpha$-Melanocyte-Stimulating Hormone Stimulates Oxytocin Release from the Dendrites of Hypothalamic Neurons While Inhibiting Oxytocin Release from Their Terminals in the Neurohypophysis
}

\author{
Nancy Sabatier, ${ }^{1}$ Céline Caquineau, ${ }^{1}$ Govindan Dayanithi, ${ }^{2}$ Philip Bull, ${ }^{1}$ Alison J. Douglas, ${ }^{1}$ Xiao Ming M. Guan, ${ }^{3}$ \\ Michael Jiang, ${ }^{3}$ Lex Van der Ploeg, ${ }^{3}$ and Gareth Leng ${ }^{1}$ \\ ${ }^{1}$ Department of Biomedical Sciences, University of Edinburgh Medical School, Edinburgh EH8 9XD, United Kingdom, ${ }^{2}$ Institut National de la Santé et de la \\ Recherche Médicale 583, University of Montpellier II, Montpellier, Cedex 5, France, and ${ }^{3}$ Departments of Medicinal Chemistry and Obesity Research, Merck \\ Research Laboratories, Rahway, New Jersey 07065
}

The peptides $\alpha$-melanocyte stimulating hormone ( $\alpha$-MSH) and oxytocin, when administered centrally, produce similar behavioral effects. $\alpha$-MSH induces Fos expression in supraoptic oxytocin neurons, and $\alpha$-MSH melanocortin-4 receptors (MC4Rs) are highly expressed in the supraoptic nucleus, suggesting that $\alpha$-MSH and oxytocin actions are not independent. Here we investigated the effects of $\alpha$-MSH on the activity of supraoptic neurons. We confirmed that $\alpha$-MSH induces Fos expression in the supraoptic nucleus when injected centrally and demonstrated that $\alpha$-MSH also stimulates Fos expression in the nucleus when applied locally by retrodialysis. Thus $\alpha$-MSH-induced Fos expression is not associated with electrophysiological excitation of supraoptic neurons because central injection of $\alpha$-MSH or selective MC4 receptor agonists inhibited the electrical activity of oxytocin neurons in the supraoptic nucleus recorded in vivo. Consistent with these observations, oxytocin secretion into the bloodstream decreased after central injection of $\alpha$-MSH. However, MC4R ligands induced substantial release of oxytocin from dendrites in isolated supraoptic nuclei. Because dendritic oxytocin release can be triggered by changes in $\left[\mathrm{Ca}^{2+}\right]_{\mathrm{i}}$, we measured $\left[\mathrm{Ca}^{2+}\right]_{\mathrm{i}}$ responses in isolated supraoptic neurons and found that MC4R ligands induce a transient $\left[\mathrm{Ca}^{2+}\right]_{\mathrm{i}}$ increase in oxytocin neurons. This response was still observed in low extracellular $\mathrm{Ca}^{2+}$ concentration and probably reflects mobilization of $\left[\mathrm{Ca}^{2+}\right]_{\mathrm{i}}$ from intracellular stores rather than entry via voltage-gated channels. Taken together, these results show for the first time that a peptide, here $\alpha$-MSH, can induce differential regulation of dendritic release and systemic secretion of oxytocin, accompanied by dissociation of Fos expression and electrical activity.

Key words: $\alpha$-melanocyte-stimulating hormone; supraoptic nucleus; oxytocin; dendritic release; electrical activity; Fos expression; $\left[\mathrm{Ca}^{2+}\right]_{\mathrm{i}}$

\section{Introduction}

$\alpha$-Melanocyte-stimulating hormone ( $\alpha$-MSH) is synthesized mainly in melanotroph cells in the intermediate lobe of the pituitary, but it also is produced in the hypothalamus by neurons in the arcuate nucleus (Watson and Akil, 1980). Fibers containing $\alpha$-MSH are present in many brain areas (O'Donohue and Jacobowitz, 1980), and $\alpha$-MSH is implicated in a variety of behavioral processes, including the stretching-yawning syndrome, grooming, pain perception, feeding behavior, and male and female sexual behavior (Bertolini and Gessa, 1981; O'Donohue and Dorsa, 1982). Central actions of $\alpha$-MSH are thought to be mediated primarily via melanocortin-3 and melanocortin-4 receptors (MC3R, MC4R) (Adan and Gispen, 1997).

Received June 19, 2003; revised Sept. 23, 2003; accepted Sept. 24, 2003

This study was supported by Merck \& Company (Darmstadt, Germany).

Correspondence should be addressed to Dr. Nancy Sabatier, Department of Biomedical Sciences, University of Edinburgh Medical School, George Square, Edinburgh EH8 9XD, UK. E-mail: n.sabatier@ed.ac.uk.

Copyright $\odot 2003$ Society for Neuroscience $\quad$ 0270-6474/03/2310351-08\$15.00/0
These behaviors are remarkably similar to those behaviors in which centrally acting oxytocin is implicated. In particular, central injections of oxytocin elicit yawning (Argiolas et al., 1986) and grooming (Drago et al., 1986), have anxiolytic effects (McCarthy and Altemus, 1997), suppress feeding (Arletti et al., 1989), and stimulate sexual behavior (Arletti and Bertolini, 1985; Arletti et al., 1985). Centrally acting oxytocin derives in part from centrally projecting parvocellular neurons of the paraventricular nucleus, but large amounts of oxytocin also are released from magnocellular oxytocin neurons in the supraoptic and paraventricular nuclei of the hypothalamus.

The paraventricular nucleus is very heterogeneous, but the supraoptic nucleus contains just magnocellular neurons that synthesize either vasopressin or oxytocin. These neurons project to the posterior pituitary where oxytocin and vasopressin are secreted into the circulation. Circulating oxytocin is important during parturition and lactation, whereas vasopressin regulates body water balance. In addition, oxytocin and vasopressin are 
released from the dendrites of magnocellular neurons, and dendritic release is regulated semi-independently of secretion from the posterior pituitary. Dendritically released peptides have autoregulatory actions on magnocellular neurons (Freund-Mercier and Richard, 1984; Ludwig and Leng, 1997; Gouzenes et al., 1998) but also may diffuse to have "neurohormonal-like" actions elsewhere. Oxytocin receptors are widespread in the CNS and are present at many sites at which no oxytocin fibers have been described. However, oxytocin concentrations in the CSF, which substantially reflect release from magnocellular neurons, are much higher than in plasma (Ludwig, 1998), indicating that oxytocin released from dendrites may diffuse through the extracellular space or via the CSF to act at distant sites.

Electrophysiological and morphological studies have reported efferent projections from the arcuate nucleus to the supraoptic nucleus (Sawchenko et al., 1982; Leng et al., 1988), and the supraoptic and paraventricular nuclei show high expression of MC4R mRNA (Mountjoy et al., 1994). Intracerebroventricular injection of $\alpha$-MSH induces expression of the immediate early gene c-fos in the supraoptic nucleus (Sabatier et al., 2003), which is normally a reliable indicator of neuronal excitation. The present study investigates the role of $\alpha$-MSH in the regulation of magnocellular oxytocin neurons.

\section{Materials and Methods}

Electrophysiology. Adult female rats were anesthetized with urethane $(1.25 \mathrm{gm} / \mathrm{kg}$, i.p.), a femoral vein and trachea were cannulated, and an injection cannula was implanted into the lateral ventricle. The pituitary stalk and supraoptic nucleus were exposed transpharyngeally, and a microdialysis probe was placed onto the ventral surface of the nucleus (Ludwig et al., 2002). A glass micropipette placed through the center of the probe loop recorded the extracellular activity of single neurons. A stimulating electrode was placed on the pituitary stalk to deliver single matched biphasic pulses ( $1 \mathrm{msec},<1 \mathrm{~mA}$ ) for antidromic identification of supraoptic neurons. Oxytocin cells were distinguished from vasopressin cells by their firing pattern and by their opposite response to intravenous CCK [20 $\mu \mathrm{g} / \mathrm{kg}$; cholecystokinin-(26-33)-sulfated; Bachem, Essex, UK] (Renaud et al., 1987; Leng et al., 1991). Some cells also were tested with intravenous phenylephrine (PE; $10 \mu \mathrm{g}$ ), which inhibits vasopressin cells with no effect on oxytocin cells (Leng et al., 1991). Artificial CSF [ACSF; pH 7.2, composition (in mM): $138 \mathrm{NaCl}, 3.36 \mathrm{KCl}, 9.52 \mathrm{NaHCO}_{3}$, $0.49 \mathrm{Na}_{2} \mathrm{HPO}_{4}, 2.16$ urea, $0.49 \mathrm{NaH}_{2} \mathrm{PO}_{4}, 1.26 \mathrm{CaCl}_{2}, 1.18 \mathrm{MgCl}_{2}$ ] was dialyzed at $3 \mu \mathrm{l} / \mathrm{min}$ and changed to ACSF containing $\alpha$-MSH (Calbiochem-Novabiochem, Nottingham, UK), MC4R agonist (MRLOB0005), or MC4R antagonist (MRLOB-0004) (Bednarek et al., 2001); the sphere of action of dialyzed peptides has been discussed previously (Ludwig and Leng, 1997). The MC4R agonist is a full, high-affinity agonist (rat MC4R $\mathrm{IC}_{50}, 0.61 ; \mathrm{EC}_{50}, 1.9 \mathrm{nM}$ ) and is $>100$-fold selective compared with other MCR subtypes). Firing rate in the $5 \mathrm{~min}$ before injection was compared with the rate between 5 and 10 min after; activity in $30 \mathrm{sec}$ bins was compared, using a Student's $t$ test, accepting $p<0.001$ as significant. Only one neuron was tested with an intracerebroventricular injection of drugs in any rat.

Blood sampling. Conscious rats were implanted with a catheter and an intracerebroventricular cannula with the tip in the left cerebral ventricle under halothane anesthesia. Then 2 days later, blood samples were taken $10 \mathrm{~min}$ before $(0.5 \mathrm{ml})$ and 10,15 , and $90 \mathrm{~min}(0.3 \mathrm{ml})$ after intracerebroventricular injection of $\alpha$-MSH ( $1 \mu \mathrm{g}$ in $5 \mu \mathrm{l})$ or vehicle $(5 \mu \mathrm{l}$ of isotonic saline) or after intravenous injection of CCK $(20 \mu \mathrm{g} / \mathrm{kg})$ or vehicle ( $0.15 \mathrm{ml}$ of isotonic saline). At $90 \mathrm{~min}$ after drug administration the rats were killed with sodium pentobarbitone and perfused transcardially with heparinized saline, followed by $4 \%$ paraformaldehyde in $0.1 \mathrm{M}$ PBS. The brains were removed, postfixed overnight, and cryoprotected in $30 \%$ sucrose at $4^{\circ} \mathrm{C}$ for analysis of Fos.

In anesthetized rats the blood samples $(0.3 \mathrm{ml})$ were withdrawn from a femoral artery. The plasma was separated by centrifugation and stored at $-20^{\circ} \mathrm{C}$. The blood cells were resuspended in $0.15 \mathrm{M} \mathrm{NaCl}$ and returned via the femoral vein.

Radioimmunoassay. Oxytocin was measured in duplicate in unextracted plasma by specific radioimmunoassay, using antibody donated by Professor T. Higuchi (Higuchi et al., 1986). Pre-iodinated oxytocin was obtained (NEX187; NEN Life Science Products, Boston, MA), and a standard curve was constructed by using the Fourth International oxytocin standard (National Institute for Biological Standards and Control, Hertfordshire, UK). The mean intra-assay coefficient of variance was $12 \pm 3 \%$, the interassay coefficient of variance was $12.5 \pm 2 \%$, and the assay sensitivity was $2.7 \pm 0.4 \mathrm{pg} / \mathrm{ml}$ at $40 \pm 7 \%$ of total binding.

Microdialysis. Rats were anesthetized with sodium pentobarbitone (60 $\mathrm{mg} / \mathrm{kg}$, i.p.); a microdialysis probe (membrane, $1 \mathrm{~mm}$ in length, $0.5 \mathrm{~mm}$ in diameter; CMA-12, CMA/Microdialysis, Stockholm, Sweden) was implanted dorsally, adjacent to the right supraoptic nucleus at coordinates rostrocaudal, 0; lateral, 1.5; depth, $9.5 \mathrm{~mm}$. Drug administration was started $2 \mathrm{hr}$ after the end of surgery. ACSF or ACSF containing $\alpha$-MSH was dialyzed at $1.5 \mu \mathrm{l} / \mathrm{min}$. Rats were killed $60 \mathrm{~min}$ after drug administration and processed as above for visualization of Fos.

Fos expression. Coronal sections of hypothalamus $(44 \mu \mathrm{m})$ were cut on a freezing microtome. Standard immunocytochemistry was performed on floating sections by using a polyclonal antibody raised in rabbit against the $\mathrm{N}$-terminal amino acids $4-17$ of the protein product of human c-fos (Ab-2, Calbiochem-Novabiochem). For double immunocytochemistry a polyclonal antibody raised in rabbit against oxytocin (Ab-1, Oncogene Research Products, San Diego, CA) was used. Antibody-antigen complexes were visualized by using $\mathrm{ABC}$ methods with a Vector stain elite kit (Vector Laboratories, Bucks, UK) intensified with nickelintensified diaminobenzidine (Ni-DAB; single immunocytochemistry) or with DAB only (double immunocytochemistry). Fos-positive nuclei and the percentage of activated cells were counted blind in the supraoptic nucleus at the level of maximal cross-sectional area. Three sections per rat were counted.

Measurement of $\left[\mathrm{Ca}^{2+}\right]_{i}$ in isolated neurons. For each experiment the supraoptic nuclei were dissected from two female Wistar rats and transferred to oxygenated Locke's buffer containing (in nM): $140 \mathrm{NaCl}, 5 \mathrm{KCl}$, $1.2 \mathrm{KH}_{2} \mathrm{PO}_{4}, 1.8 \mathrm{CaCl}_{2}, 10$ glucose, 10 HEPES-NaOH, pH 7.2, at $290-$ $310 \mathrm{mOsm} / \mathrm{l}$ (Lambert et al., 1994). Low-Ca ${ }^{2+}$ EGTA buffer was prepared by using Locke's buffer supplemented with EGTA (Sigma, Poole, UK). The final concentration of $\mathrm{Ca}^{2+}$ in low-Ca ${ }^{2+}$ EGTA buffer was 122 nM. Tissue was dissociated in Locke's buffer supplemented with enzymes deoxyribonuclease I $(0.5 \mathrm{mg} / \mathrm{ml})$, protease X $(1 \mathrm{mg} / \mathrm{ml})$, and protease XIV $(1 \mathrm{mg} / \mathrm{ml})$, followed by trituration. Cells then were incubated with $2.5 \mu \mathrm{M}$ fura-2 AM plus $0.02 \%$ pluronic F-127 (Molecular Probes, Eugene, OR). Fluorescence measurements of $\left[\mathrm{Ca}^{2+}\right]_{\mathrm{i}}$ were performed with a fast fluorescence microspectrofluorometry system (FFP; Zeiss, Oberkochen, Germany), using an inverted microscope equipped for epifluorescence (Lambert et al., 1994).

Oxytocin dendritic release. Female rats were decapitated, and two supraoptic nuclei (for each experiment) were dissected and transferred into Locke's buffer. Samples were collected every $5 \mathrm{~min}$. $\alpha$-MSH or MC4R agonist was applied for $5 \mathrm{~min}$, MC4R antagonist for $10 \mathrm{~min}$, and low$\mathrm{Ca}^{2+}$ EGTA buffer for $20 \mathrm{~min}$. Oxytocin was measured by radioimmunoassay (Ludwig et al., 2002).

\section{Results}

\section{$\alpha$-MSH inhibits the electrical activity of oxytocin neurons}

Experiments to determine the effects of $\alpha$-MSH or MC4R agonist were performed on 30 identified oxytocin cells and seven identified vasopressin cells. Agonists were tested by intracerebroventricular injection in 22 oxytocin cells and five vasopressin cells and by retrodialysis in eight oxytocin cells and two vasopressin cells. Each cell represents an independent experiment in a different rat.

$\alpha$-MSH (200-300 ng, i.c.v.) produced a rapid, reversible inhibition of each of five identified oxytocin neurons that were tested (Fig. 1 A1,A2; mean change in firing rate, $1.2 \pm 0.02$ spikes/ sec from an initial rate of $3.7 \pm 0.8$ spikes $/ \mathrm{sec}$ ). To test whether this was mediated by MC4R, we used a highly specific MC4R 

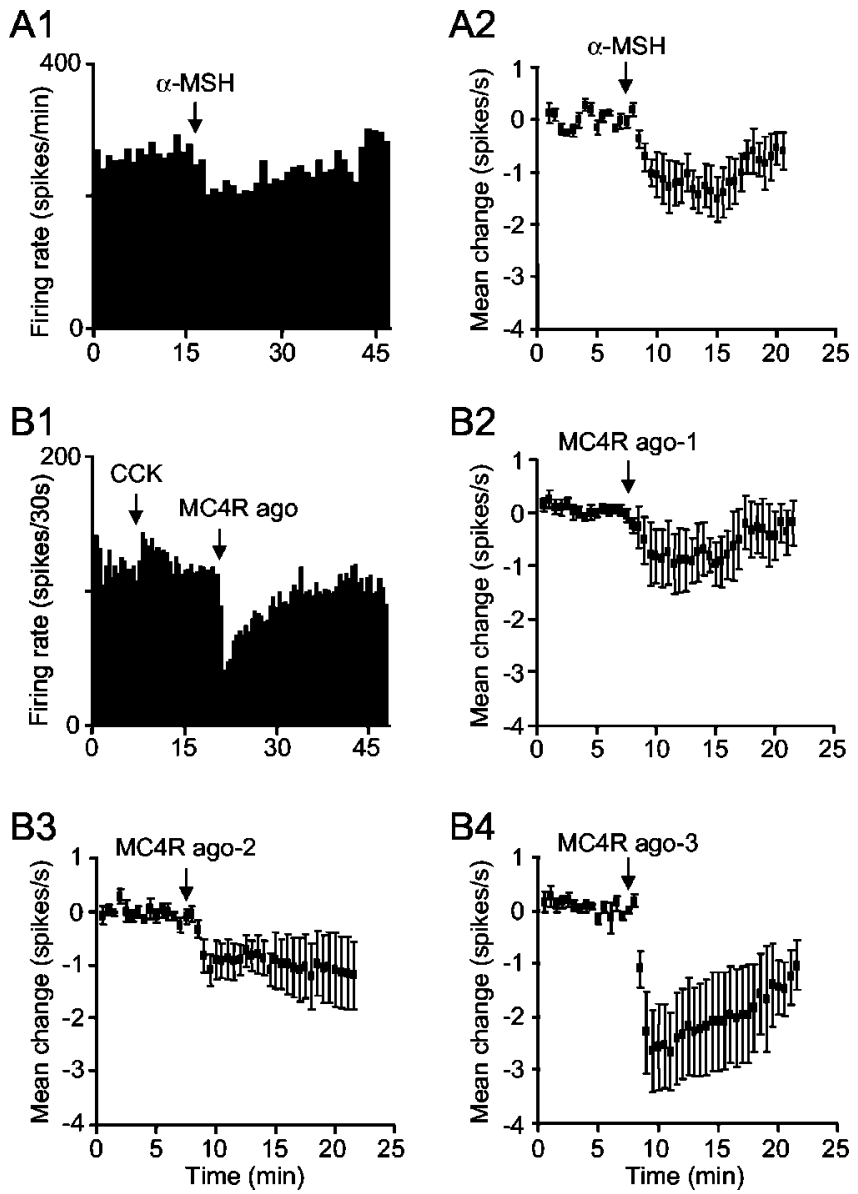

Figure 1. Effect of $\alpha$-MSH and MC4R agonist on oxytocin neurons. A1, Example of reversible inhibition induced by $\alpha$-MSH ( $200 \mathrm{ng}$, i.c.v.). $A 2$, The mean change in firing rate ( $\pm \mathrm{SE}$ ) of five neurons in response to $\alpha$-MSH (200-300 ng, i.c.v.). B1, Inhibition of a representative oxytocin neuron (identified by its activation after intravenous injection of $20 \mu \mathrm{g} / \mathrm{kg}(\mathrm{CK}$ ) in response to MC4R agonist (100 ng, i.c.v.). B2-B4, The inhibition induced by MC4R agonist is dosedependent. Data show the mean changes in firing rate $( \pm S E)$ after MC4R agonist at $50-100 \mathrm{ng}$ (MC4Rago- $1 ; n=6 ; B 2)$, $200 \mathrm{ng}$ (MC4Rago-2; $n=6 ; B 3$ ), and 400 $-500 \mathrm{ng}$ (MC4R ago- $3 ; n=$ $5 ; B 4)$.

agonist. Intracerebroventricular injection of the agonist inhibited oxytocin neurons in a dose-dependent manner (Fig. 1 B1-B4). In contrast, vasopressin neurons were not affected significantly by intracerebroventricular MC4R agonist (200 ng; $n=4$; Fig. $2 A, B$ ). One vasopressin neuron was tested with intracerebroventricular $\alpha$-MSH (200 ng) and also was not affected (data not shown).

To test whether $\alpha$-MSH acts directly on the supraoptic nucleus, we applied $\alpha$-MSH to the nucleus by retrodialysis. The firing rate of neurons in the 5 min before retrodialysis was compared with the rate between 15 and 20 min after beginning application. Four of five oxytocin neurons, each from a different rat, were inhibited by $\alpha$-MSH at dialysate concentrations of 1-3.4 $\mu \mathrm{g} / \mu \mathrm{l}$ (Fig. $3 A, B$ ), whereas the fifth was unaffected. Two of three other oxytocin neurons were inhibited by retrodialysis of MC4R agonist $(0.65 \mu \mathrm{g} / \mu \mathrm{l})$, with no effect on the third. The firing rate of one vasopressin neuron tested with retrodialysis of $\alpha$-MSH (1.6 $\mu \mathrm{g} / \mu \mathrm{l})$ and in one vasopressin neuron tested with retrodialysis of MC4R agonist $(0.65 \mu \mathrm{g} / \mu \mathrm{l})$ was not affected.

$\alpha$-MSH inhibits oxytocin secretion from the posterior pituitary

These electrophysiological experiments indicated that MC4R ligands inhibit oxytocin cells after intracerebroventricular injec-
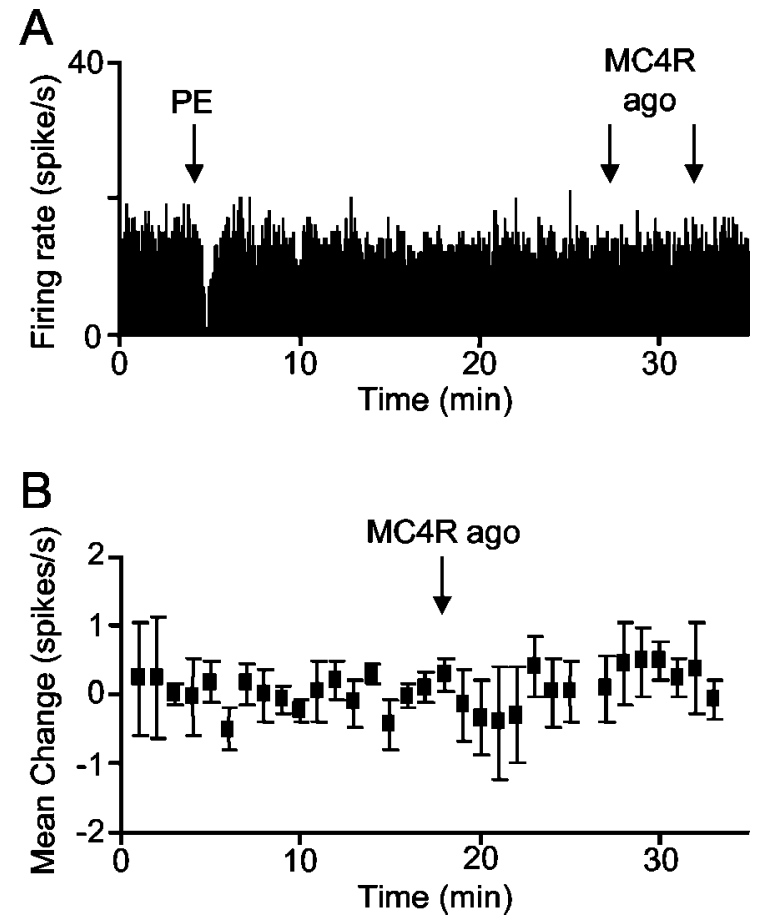

Figure 2. Effect of MC4R agonist on vasopressin neurons. $A$, Example showing that intracerebroventricular injection of MC4R agonist ( $200 \mathrm{ng}$ ) had no effect on the firing rate of vasopressin neurons recorded from the supraoptic nucleus (identified by inhibition after intravenous injection of $10 \mu \mathrm{g}$ of $\mathrm{PE}$ ). $B$, Mean change ( $\pm \mathrm{SE}$ ) in the firing rate of four vasopressin neurons after intracerebroventricular injection of $200 \mathrm{ng}$ of MC4R agonist.

tion, but previous studies of Fos expression suggested excitatory effects. To get an independent measure of the effects of MC4R ligands, we measured plasma oxytocin. In urethane-anesthetized rats intracerebroventricular injection of MC4R agonist (400 ng) produced a significant fall in the mean oxytocin concentration (from $20.5 \pm 3 \mathrm{pg} / \mathrm{ml}$ before intracerebroventricular injection down to $13.3 \pm 3.3 \mathrm{pg} / \mathrm{ml}$ at $15 \mathrm{~min}$ after injection; mean change, $7.1 \pm 2.2 \mathrm{pg} / \mathrm{ml} ; n=7$; Friedman's repeated measures ANOVA on ranks followed by Dunnett's test; $p<0.05$ at 15 and at $20 \mathrm{~min}$ after injection), whereas no significant change followed intracerebroventricular vehicle $(21.1 \pm 2 \mathrm{pg} / \mathrm{ml}$ before injection; $19.2 \pm$ $2.3 \mathrm{pg} / \mathrm{ml}$ at $15 \mathrm{~min}$ after injection; mean change, $1.6 \pm 2.7 \mathrm{pg} / \mathrm{ml}$; $n=6)$. To see inhibitory effects more clearly, we tested the effects of MC4R agonist on oxytocin secretion prestimulated by intraperitoneal injection of hypertonic saline. Intracerebroventricular injection of MC4R agonist produced a clear fall in oxytocin concentration in all rats (Fig. $4 A$ ), whereas vehicle injection was ineffective.

The electrophysiological experiments were performed in urethane-anesthetized rats, as were these secretion experiments, but previous Fos studies (Olszewski et al., 2001) were performed in conscious rats. It seemed possible, therefore, that $\alpha$-MSH has different effects in conscious and anesthetized rats, so we performed further secretion experiments in conscious rats. Plasma oxytocin concentrations were much lower in conscious rats and close to the limit of detection, so as a positive control for our ability to detect stimulation of secretion we gave one group of rats an intravenous injection of CCK. CCK injection evoked an increase in oxytocin concentration as expected (Verbalis et al., 1986), whereas an intracerebroventricular injection of $\alpha$-MSH or vehicle had no significant effect (Fig. $4 B$ ); the low basal levels in these rats meant that inhibitory actions would be undetectable. 
A
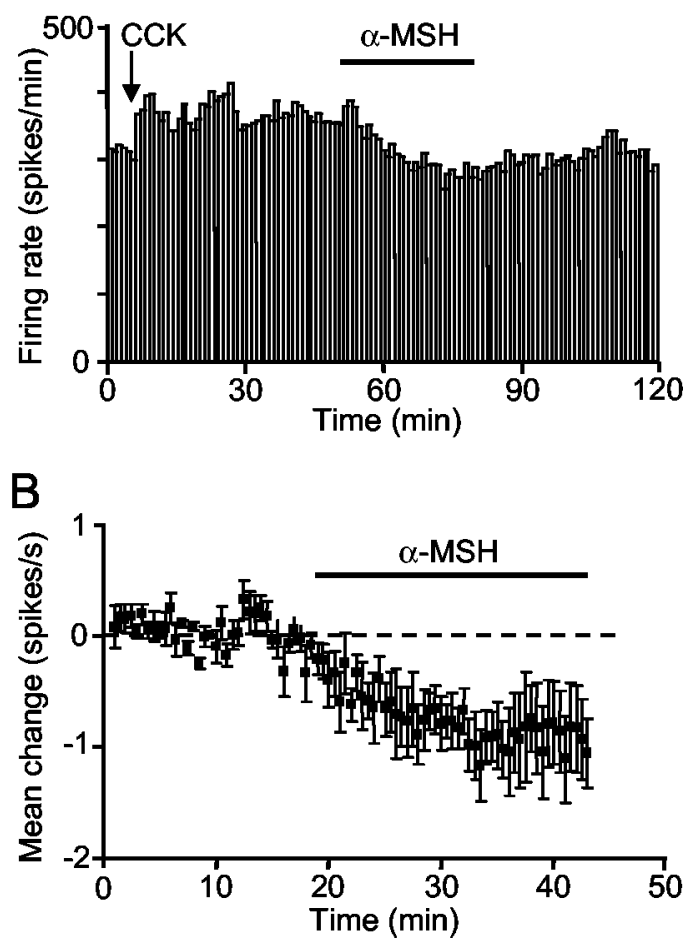

Figure 3. Effect of $\alpha$-MSH retrodialyzed directly onto the supraoptic nucleus. $A$, Example of an oxytocin neuron (identified by its activation after intravenous injection of $(\mathrm{CK}$ ) inhibited by retrodialysis of $\alpha$-MSH (3.4 $\mu \mathrm{g} / \mu \mathrm{l})$. B, Mean change ( $\pm \mathrm{SE}$ ) in the firing rate of five oxytocin neurons during retrodialysis of $\alpha$-MSH $(1-3.4 \mu \mathrm{g} / \mu \mathrm{l})$. The dashed line indicates the reference (zero change) level.

The brains from these rats were taken for analysis of Fos expression to compare the extent of Fos induction in response to CCK and $\alpha-\mathrm{MSH}$.

\section{$\alpha$-MSH induces Fos expression in oxytocin neurons}

In each of seven conscious rats injected intracerebroventricularly with $\alpha$-MSH ( $1 \mu \mathrm{g})$, widespread Fos expression was observed in the supraoptic nucleus (Fig. 5B). As expected (Hamamura et al., 1991), systemic injection of CCK $(20 \mu \mathrm{g} / \mathrm{kg}$, i.v. $)$ in eight rats induced Fos expression in the dorsal supraoptic nucleus [Fig. $5 C$; $55 \pm 11$ Fos-positive cells/section, significantly more than in rats injected with intravenous vehicle (Fig. 5A)]. Systemic (intraperitoneal) injection of hypertonic saline $(1.5 \mathrm{M} \mathrm{NaCl})$ in three rats induced intense Fos expression in the nucleus (Fig. 5D; $337 \pm 33$ cells/section). In rats injected with intracerebroventricular $\alpha$-MSH there were $110 \pm 19$ Fos-positive cells/section in the supraoptic nucleus, significantly more than either intracerebroventricular vehicle-injected rats or CCK-injected rats (Fig. 5E). Double immunohistochemistry confirmed that this induction included oxytocin neurons (mean proportion of oxytocin neurons that contain Fos: $52 \pm 5 \%$ in $\alpha$-MSH-treated rats, $n=8$; $37 \pm 6 \%$ in CCK-treated rats, $n=8$ ).

In further experiments in 11 anesthetized rats $\alpha$-MSH or vehicle was microdialyzed in the close vicinity of the supraoptic nucleus (Fig. 6A). In rats microdialyzed with $\alpha$-MSH $(1.7 \mu \mathrm{g} / \mu \mathrm{l}$ for $30 \mathrm{~min}$ ) Fos expression was significantly higher in the ipsilateral supraoptic nucleus (Fig. $6 C ; 14.2 \pm 4.6$ cells/section) than in the control, contralateral nucleus (Fig. $6 B ; 7.7 \pm 3.3$ cells/section; $p<0.05$; mean ipsilateral-contralateral difference, $7 \pm 1.8$ cells/ section; $n=6$ ). In contrast, in rats microdialyzed with vehicle
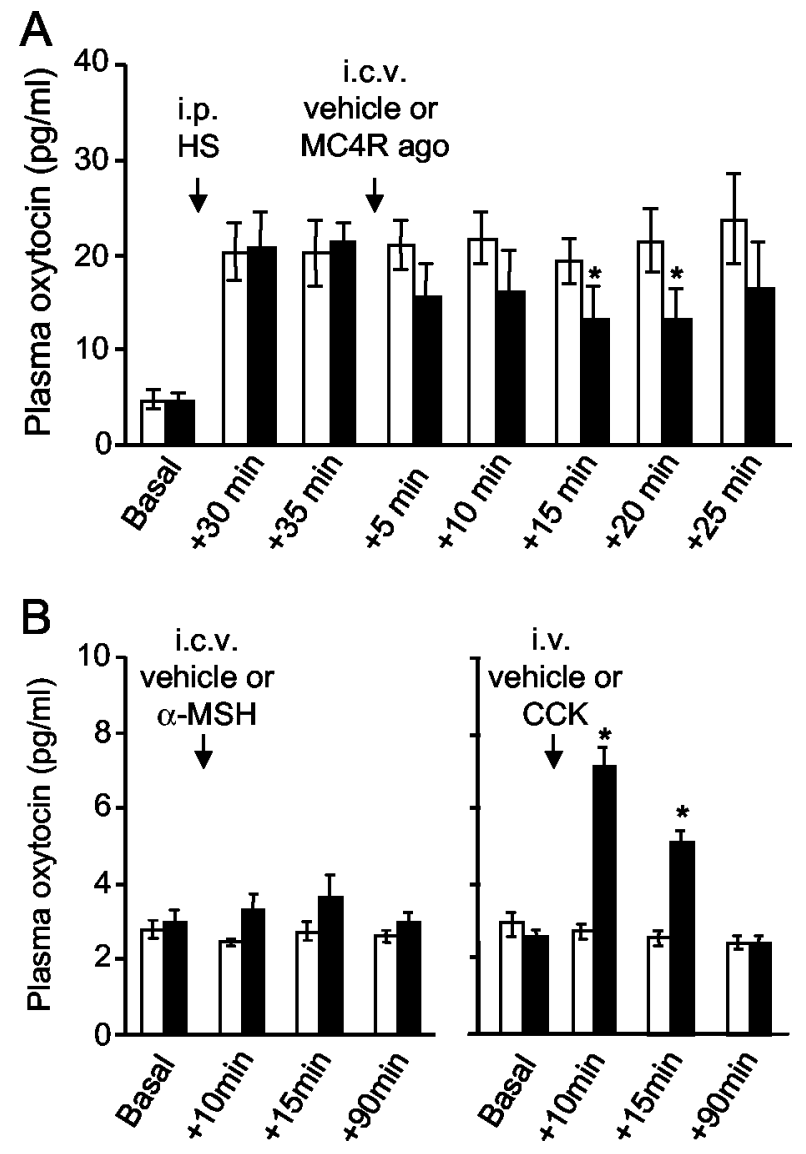

Figure 4. Effect of MC4R ligands on systemic secretion of oxytocin. A, Mean plasma oxytocin concentration ( $\pm \mathrm{SE}$ ) in anesthetized rats after intraperitoneal injection of hypertonic saline (HS) and intracerebroventricular injection of $400 \mathrm{ng}$ of MC4R agonist (black bars; $n=7$ ) or vehicle (white bars; $n=5$ ). Note the decrease in oxytocin concentration after MC4R agonist (one-way repeated-measures ANOVA followed by post hoc $t$ test; ${ }^{*} p<0.05$ ). $B$, Oxytocin concentration in conscious rats after intracerebroventricular injection of $1 \mu \mathrm{g}$ of $\alpha$-MSH (black bars) or vehicle (white bars) and after intravenous injection of $20 \mu \mathrm{g} / \mathrm{kg}$ CCK (black bars; $n=7$ ) or vehicle (white bars; $n=6$ ). CCK induced a significant increase in oxytocin secretion $\left({ }^{*} p<\right.$ 0.05), whereas intracerebroventricular injection of MC4R agonist was ineffective.

there was no difference between ipsilateral and contralateral nuclei (mean difference, $0.4 \pm 1.7 ; n=5$ ) and significantly less than in $\alpha$-MSH-infused rats $(p<0.05)$, confirming that this induction was not attributable to introduction of the microdialysis probe.

$\alpha$-MSH stimulates $\left[\mathrm{Ca}^{2+}\right]_{\mathrm{i}}$ increase in oxytocin neurons

Vasopressin and oxytocin neurons were freshly isolated and identified according to their selective $\left[\mathrm{Ca}^{2+}\right]_{\mathrm{i}}$ responses to vasopressin and oxytocin (Lambert et al., 1994; Dayanithi et al., 1996). In 10 oxytocin neurons $1 \mu \mathrm{M} \alpha$-MSH induced a transient $\left[\mathrm{Ca}^{2+}\right]_{\mathrm{i}}$ increase (Fig. 7A), with a mean peak amplitude $( \pm \mathrm{SE})$ of $307 \pm$ $52 \mathrm{nM}$ (range, 110-500 nM). In six oxytocin neurons MC4R agonist at $1 \mu \mathrm{M}$ also induced an increase in $\left[\mathrm{Ca}^{2+}\right]_{\mathrm{i}}$; however, this response was smaller ( $89 \pm 39 \mathrm{nM}$; range, $29-54 \mathrm{~nm})$ than to $\alpha$-MSH (Fig. 7B).

The mean $\left[\mathrm{Ca}^{2+}\right]_{\mathrm{i}}$ response to $1 \mu \mathrm{M} \alpha$-MSH $(216 \pm 39 \mathrm{nM})$ was reduced by $49 \%$ (to $110 \pm 40 \mathrm{nM}$ ) in the presence of a MC4R antagonist at $1 \mu \mathrm{M}(n=6$; Fig. $7 C)$. The MC4R antagonist at 500 $\mathrm{nm}$ inhibited the mean $\left[\mathrm{Ca}^{2+}\right]_{\mathrm{i}}$ response to $100 \mathrm{~nm} \alpha-\mathrm{MSH}$ $(197 \pm 19 \mathrm{~nm})$ by $87 \%$ (to $26 \pm 17 \mathrm{~nm} ; n=4)$.

In four oxytocin neurons that were tested, $\alpha$-MSH induced a response in a low $\mathrm{Ca}^{2+}$ EGTA buffer (Fig. 7D), indicating that the 

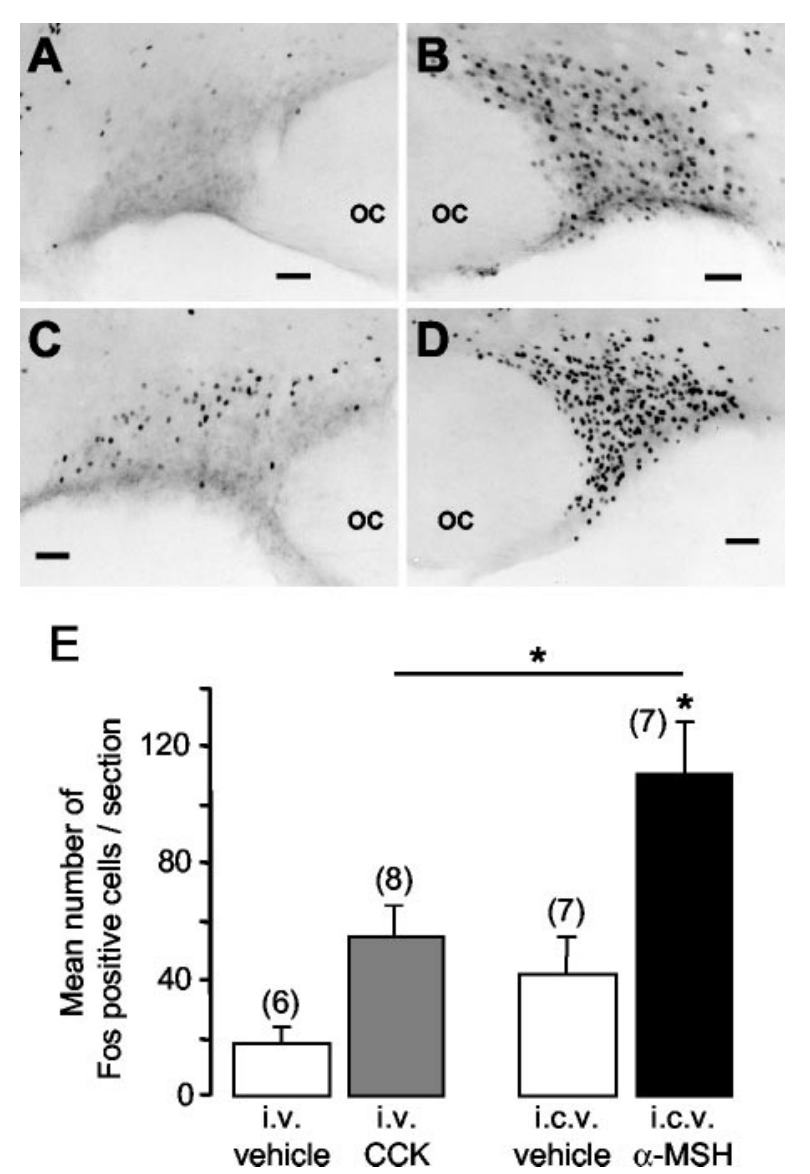

Figure 5. Fos immunoreactivity in the supraoptic nucleus after systemic injection of vehicle (A) (isotonic saline), intracerebroventricular injection of $1 \mu \mathrm{g} \alpha-\mathrm{MSH}(B)$, systemic injection of CCK (C), and intraperitoneal injection of hypertonic saline (D). OC, Optic chiasm. Scale bars, 100 $\mu \mathrm{m}$. $E$, Mean $\pm \mathrm{SE}$ the number of Fos-positive cells/section per group; the number of rats per group is in parentheses $\left({ }^{*} p<0.05\right.$; Mann-Whitney test).

response reflects $\mathrm{Ca}^{2+}$ release from intracellular stores rather than entry via voltage-gated channels.

Neither $\alpha$-MSH (Fig. 7E) nor MC4 agonist had any effect on $\left[\mathrm{Ca}^{2+}\right]_{\mathrm{i}}$ in vasopressin cells $(n=5)$.

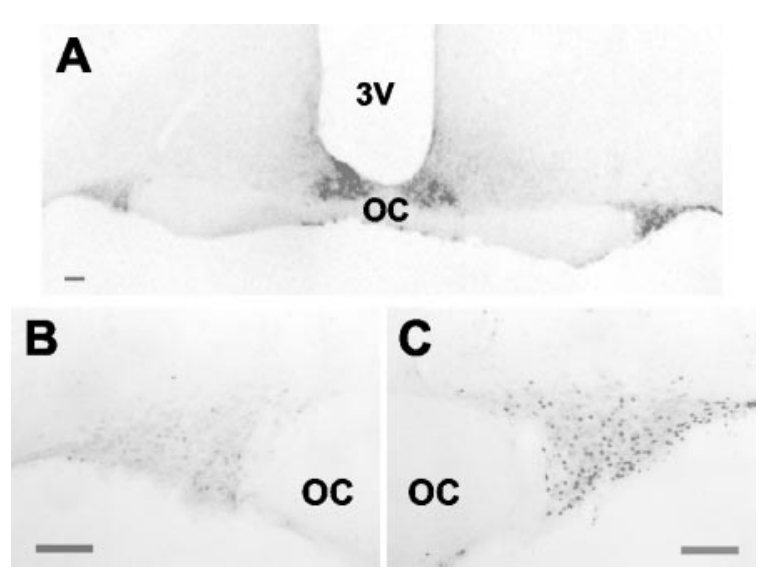

Figure 6. Effect of local retrodialysis of $\alpha$-MSH on Fos expression in the supraoptic nucleus. $A$, Photomicrograph of a hypothalamic section from a rat after local retrodialysis of $\alpha$-MSH. Also shown is Fos immunoreactivity in the contralateral $(B)$ or ipsilateral $(C)$ supraoptic nucleus in the same section. OC, Optic chiasm. Scale bars, $100 \mu \mathrm{m}$.
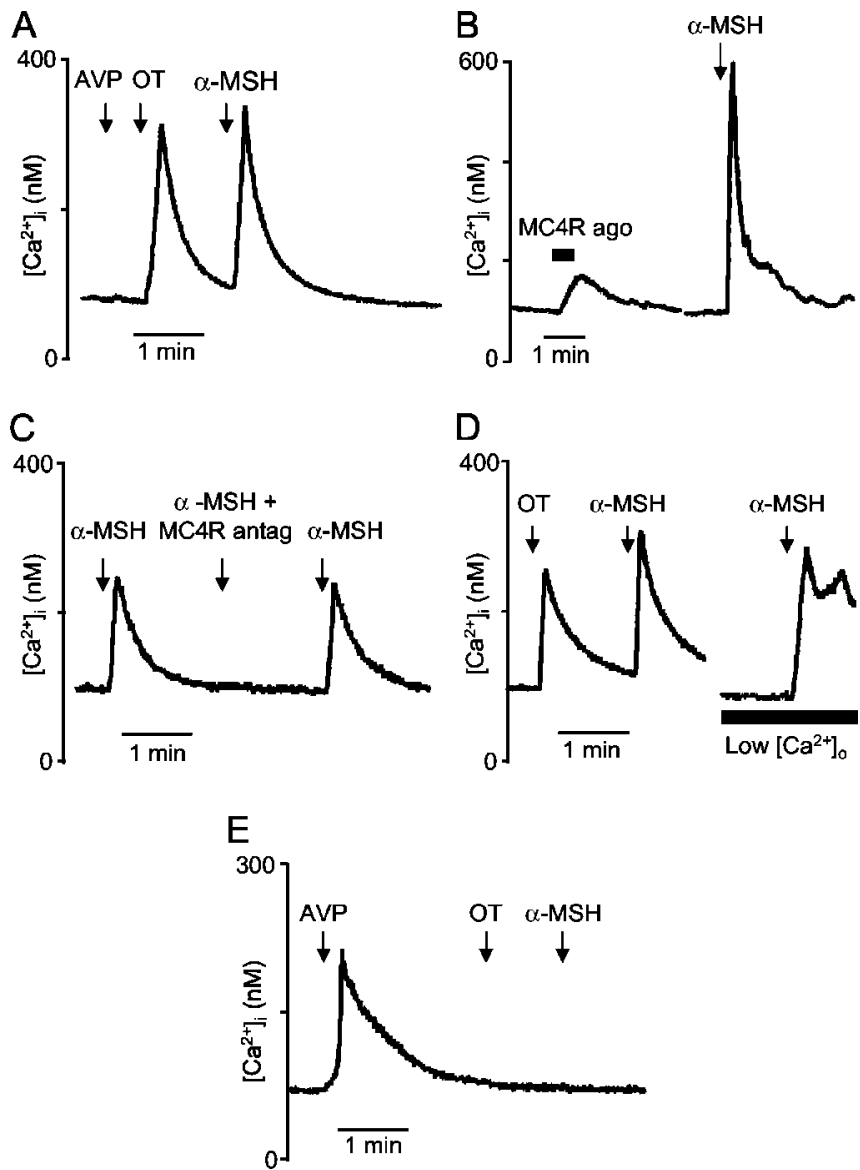

Figure 7. Effect of $\alpha$-MSH and MC4R ligands on $\left[\mathrm{Ca}^{2+}\right]_{\mathrm{i}}$ in isolated supraoptic neurons. $A$, Typical example of transient increase in $\left[\mathrm{Ca}^{2+}\right]_{\mathrm{i}}$ induced by $\alpha$-MSH $(1 \mu \mathrm{m})$ in an oxytocin neuron identified by its $\mathrm{Ca}^{2+}$ response to oxytocin (100 nM) and the absence of response to vasopressin $(100 \mathrm{~nm}) . B$, In an oxytocin neuron, an example of a typical $\left[\mathrm{Ca}^{2+}\right]_{i}$ response to MC4R agonist compared with $\alpha$-MSH response. C, Example of a neuron in which the $\left[\mathrm{Ca}^{2+}\right]_{\mathrm{i}}$ response induced by $\alpha$-MSH (100 nM) was suppressed reversibly in the presence of the MC4R antagonist ( $500 \mathrm{~nm})$. D, Typical example showing that, in an oxytocin neuron, $\alpha-\mathrm{MSH}(100 \mathrm{~nm})$ still triggered a $\left[\mathrm{Ca}^{2+}\right]_{i}$ increase in the presence of low-Ca ${ }^{2+}$ EGTA buffer. $E$, Typical example of absence of $\left[\mathrm{Ca}^{2+}\right]_{\mathrm{i}}$ response to $\alpha$-MSH $(1 \mu \mathrm{M})$ in a vasopressin neuron identified by its $\mathrm{Ca}^{2+}$ response to vasopressin (100 $\mathrm{nm}$ ) and its absence of response to oxytocin (100 nM).

\section{$\alpha$-MSH stimulates dendritic release of oxytocin}

Dendritic oxytocin release can be triggered directly by changes in $\left[\mathrm{Ca}^{2+}\right]_{\mathrm{i}}$ (Ludwig et al., 2002). We therefore tested whether $\alpha$-MSH stimulates dendritic oxytocin release in vitro in isolated supraoptic nuclei. In each of five experiments a 5 min application of $\alpha$-MSH ( $1 \mu \mathrm{M})$ induced oxytocin release that was blocked in the presence of the MC4R antagonist ( $1 \mu \mathrm{M}$; Fig. $8 A$ ). Similarly, in three experiments a 5 min application of MC4R agonist ( $1 \mu \mathrm{M})$ induced oxytocin release, and this also was blocked in the presence of the MC4R antagonist ( $1 \mu \mathrm{M}$; Fig. $8 B$ ). Oxytocin release induced by $\alpha$-MSH was not blocked by lowering extracellular $\mathrm{Ca}^{2+}$, suggesting that $\alpha$-MSH-induced $\left[\mathrm{Ca}^{2+}\right]_{\mathrm{i}}$ mobilization is sufficient to stimulate release (Fig. $8 C$ ).

\section{Discussion}

Here we show that $\alpha$-MSH has a selective modulatory action on oxytocin neurons in the supraoptic nucleus via MC4R. Central administration of $\alpha$-MSH induces Fos expression in oxytocin neurons and dendritic release of oxytocin, but it inhibits their firing rate and decreases oxytocin secretion from the pituitary gland. Thus induction of c-fos is not necessarily a sign of electrical 
A

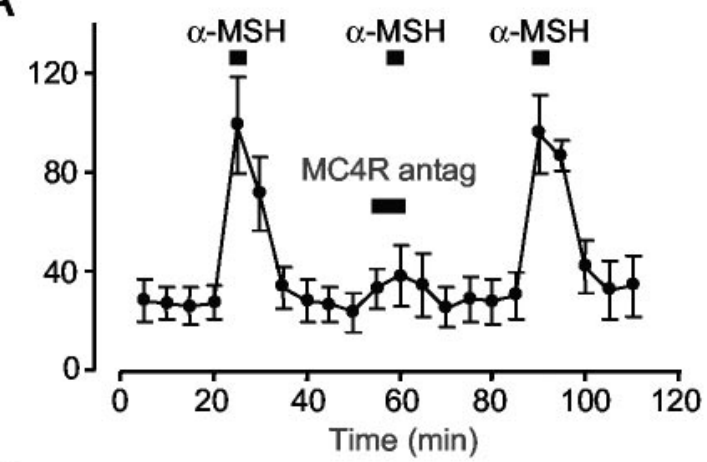

B
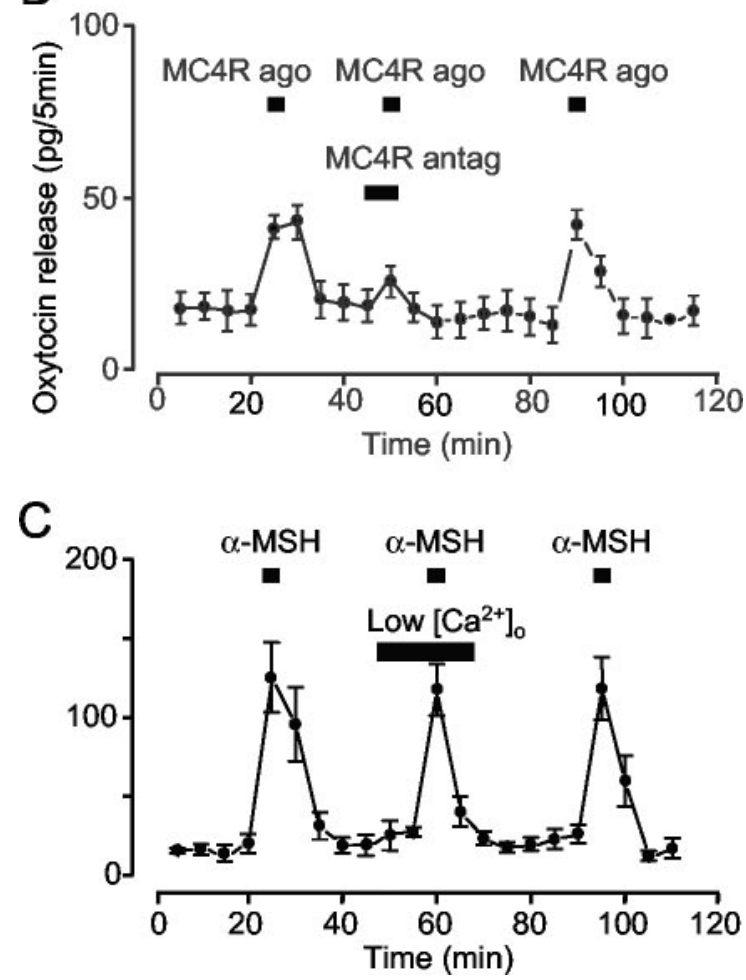

Figure 8. Effect of $\alpha$-MSH and MC4R ligands on dendritic release of oxytocin. Release from isolated supraoptic nuclei induced by $1 \mu \mathrm{M} \alpha$-MSH $(n=5 ; A)$ or $1 \mu \mathrm{M}$ MC CR agonist $(n=5 ; B)$ is blocked reversibly by $1 \mu \mathrm{M} M C 4 R$ antagonist. $C, \alpha$-MSH still triggers the release of oxytocin in the presence of low-Ca ${ }^{2+}$ EGTA buffer $(n=4)$. Error bars show SEM. In $A$ and $B$, evoked release is significantly lower in the presence of the antagonist (paired $t$ tests, all $p<0.05$ ).

excitation in supraoptic neurons but may accompany neuronal inhibition.

Enzymatic cleavage of pro-opiomelanocortin (POMC) generates several peptides, including $\alpha$-MSH, adrenocorticotropic hormone (ACTH), and endorphins. Most POMC neurons have their cell bodies in the arcuate nucleus, and some of these project to the supraoptic nucleus. ACTH-containing fibers penetrate the dorsal supraoptic nucleus, a region rich in oxytocin cells (Sawchenko et al., 1982), and immunocytochemical and retrograde-tracing studies have shown that arcuate neurons containing $\beta$-endorphin project to the supraoptic nucleus (Douglas et al., 2002). $\alpha$-MSH, ACTH, and $\beta$-endorphin all coexist within arcuate neurons (Bloch et al., 1979) and are likely to be coreleased. $\beta$-Endorphin is believed to inhibit oxytocin neurons via $\mu$-opioid receptors (Douglas et al., 1995), but although electrical stimulation of the arcuate nucleus inhibits oxytocin neurons, this inhibition is not blocked by naloxone (Leng et al., 1988), indicat- ing that non-opioid transmitters also are involved. In part at least, this inhibition is mediated by GABA (Ludwig and Leng, 2000), and blocking $\mathrm{GABA}_{\mathrm{A}}$ receptors reveals a long-lasting excitatory effect of arcuate nucleus stimulation. Thus there are both excitatory and inhibitory influences of the arcuate nucleus on oxytocin neurons.

The inhibitory effect of MC4R ligands on oxytocin secretion could be seen only in urethane-anesthetized rats, whereas these ligands showed no effect in conscious rats. Urethane is the one anesthetic that preserves normal physiological function in the oxytocin cells, in particular the milk-ejection reflex, which is impaired by most anesthetics, and for this reason is the anesthetic of general choice for study of this system (see Leng and Dyball, 1991). Urethane actually activates the neurons via its mild hyperosmotic effect. This is "physiological" in the sense that supraoptic neurons are physiologically osmoreceptive. The apparent discrepancy in the effects of MC4R ligands on oxytocin secretion in anesthetized and conscious rats occurs because in conscious rats the basal oxytocin secretion is very low and cannot be suppressed even by powerful inhibitors. So that the inhibition of secretion could be observed, it is thus essential to raise activity above the basal level, but the study on Fos expression then would be impossible to interpret.

Previous studies have shown that intracerebroventricular injections of $\alpha$-MSH and MCR agonist MTII induce Fos expression in the supraoptic nucleus (Thiele et al., 1998; Olszewski et al., 2001). These studies have been interpreted as indicating that melanocortin ligands excite supraoptic neurons, because Fos expression generally is assumed to indicate an increase in neuronal electrical activity (Sagar and Sharp, 1993; Hoffman and Lyo, 2002). In magnocellular neurons Fos expression is activated by a wide range of stimuli that increase secretion of oxytocin or vasopressin from the neurohypophysis (Giovannelli et al., 1990; Hoffman et al., 1993; Leng et al., 1999). However, we show here that $\alpha$-MSH decreases the firing rate of oxytocin neurons when applied either intracerebroventricularly or directly onto the supraoptic nucleus, does not trigger oxytocin secretion into the circulation, and yet stimulates strong expression of Fos. Oxytocin cells were recorded for up to $2 \mathrm{hr}$ after inhibition by MC4R ligands, and we never observed a subsequent period of activation that could be a later cause for Fos expression. In addition, secretion data from blood sampling showed no late stimulation of secretion. To our knowledge this is the first direct demonstration that induction of Fos expression in neurons can be accompanied by the inhibition of electrical activity. This long has been recognized as a possibility, although it generally is disregarded in the absence of a clear demonstration. In fact, we know of no system in which Fos expression in an identified neuronal population is associated with no response or inhibition of electrical activity. However, there are examples in which increased electrical activity is not accompanied by Fos expression. Luckman et al. (1994) showed that increased spike activity induced by antidromic stimulation in supraoptic neurons is not effective in inducing Fos expression, and Sgambato et al. (1997) showed a lack of Fos expression in substantia nigra despite electrophysiological excitation evoked by cortical stimulation.

We also show that $\alpha$-MSH can induce an increase in $\left[\mathrm{Ca}^{2+}\right]_{\mathrm{i}}$ in oxytocin neurons, probably by mobilizing calcium from intracellular stores, because the response persisted in the absence of extracellular calcium. This action involves MC4R, as we showed by using a specific MC4R agonist and antagonist. This is consistent with reports that MC4R mRNA is highly expressed in the supraoptic nucleus, whereas MC3R mRNA does not seem to be 
expressed there (Mountjoy et al., 1994). MC4Rs, which notably mediate the role of $\alpha-\mathrm{MSH}$ in feeding behavior (Vergoni and Bertolini, 2001), are G-protein-coupled receptors and activate the adenylyl cyclase/protein kinase A intracellular signaling pathway. However, when expressed in HEK293 cells, these receptors can trigger an increase in $\left[\mathrm{Ca}^{2+}\right]_{\mathrm{i}}$ in response to $\alpha$-MSH that results from mobilization of calcium from intracellular stores (Mountjoy et al., 2001). In oxytocin neurons the amplitude of the MC4R agonist-induced $\left[\mathrm{Ca}^{2+}\right]_{\mathrm{i}}$ responses was less than that obtained with $\alpha$-MSH, although this agonist has higher affinity and selectivity for MC4R than $\alpha$-MSH. It is possible that, although fully binding to the receptor, the agonist preferentially activates the cAMP pathway and, to a lesser extent, the intracellular $\mathrm{Ca}^{2+}$ pathway.

Intracellular calcium is a primary regulator of c-fos transcription (Morgan and Curran, 1988) via both calcium response elements and cAMP response elements in the c-fos promoter. Indeed, the ubiquity of association between neuronal excitation and Fos expression is thought to reflect the universal nature of voltage-activated calcium entry into neurons. However, calcium entry during action potential discharge is not sufficient to induce Fos expression in magnocellular neurons (Luckman et al., 1994), and other intracellular pathways are necessary. In particular, the $\alpha$-MSH-elicited mobilization of intracellular calcium may be responsible for the induction of Fos expression in oxytocin neurons by $\alpha$-MSH.

The inhibition of electrical activity appears likely to include a direct component, because topically applied $\alpha$-MSH inhibited oxytocin neurons. This may reflect hyperpolarization via $\mathrm{Ca}^{2+}$ dependent $\mathrm{K}^{+}$conductances, as shown for instance in the substantia nigra (Fiorillo and Williams, 1998). Another electrophysiological study, performed in vitro on hypothalamic slices, has reported inhibitory actions of $\alpha$-MSH on ventromedial hypothalamic neurons and paraventricular neurons (Fong and Van der Ploeg, 2000).

Whereas $\alpha$-MSH inhibits oxytocin neurons and inhibits oxytocin secretion into the circulation, $\alpha$-MSH nevertheless stimulates the central release of oxytocin from magnocellular neurons. Oxytocin is released in large amounts within the supraoptic nucleus from the neuronal dendrites. This dendritic release can occur independently of systemic secretion (Ludwig, 1998) and is not stimulated normally by action potential discharge (Ludwig et al., 2002). Recently, we have shown (Ludwig et al., 2002) that agents that mobilize intracellular calcium in oxytocin neurons, including oxytocin itself (Lambert et al., 1994), elicit dendritic oxytocin release without increasing electrical activity and without inducing secretion from nerve terminals. Furthermore, mobilization of intracellular calcium can make dendritic stores of oxytocin available for subsequent release in response to electrical activation.

Peptides released from dendrites are potentially important modulators of many functions in the CNS, because they can act locally or diffuse in the brain far from their site of release. The dendritic plexus of the magnocellular neurosecretory system is a major site of "neurohormonal" release within the brain. It seems possible, therefore, that $\alpha$-MSH can trigger oxytocin release from this site specifically and that this oxytocin release may participate in behavioral actions of $\alpha$-MSH.

\section{References}

Adan RAH, Gispen WH (1997) Brain melanocortin receptors: from cloning to function. Peptides 18:1279-1287.

Argiolas A, Melis MR, Gessa GL (1986) Oxytocin: an extremely potent in- ducer of penile erection and yawning in male rats. Eur J Pharmacol 130:265-272.

Arletti R, Bertolini A (1985) Oxytocin stimulates lordosis behavior in female rats. Neuropeptides 6:247-253.

Arletti R, Bazzani C, Castelli M, Bertolini A (1985) Oxytocin improves male copulatory performance in rats. Horm Behav 19:14-20.

Arletti R, Benelli A, Bertolini A (1989) Influence of oxytocin on feeding behavior in the rat. Peptides 10:89-93.

Bednarek MA, MacNeil T, Kalyani RN, Tang R, Van der Ploeg LH, Weinberg DH (2001) Selective, high-affinity peptide antagonists of $\alpha$ melanotropin action at human melanocortin receptor 4: their synthesis and biological evaluation in vitro. J Med Chem 44:3665-3672.

Bertolini A, Gessa GL (1981) Behavioral effects of ACTH and MSH peptides. J Endocrinol Invest 4:241-251.

Bloch B, Bugnon C, Fellmann D, Lenys D, Gouget A (1979) Neurons of the rat hypothalamus reactive with antisera against endorphins, ACTH, MSH, and $\beta$-LPH. Cell Tissue Res 204:1-15.

Dayanithi G, Widmer H, Richard PH (1996) Vasopressin-induced intracellular $\mathrm{Ca}^{2+}$ increase in isolated rat supraoptic cells. J Physiol (Lond) 490:713-727.

Douglas AJ, Neumann I, Meeren HK, Leng G, Johnstone LE, Munro G, Russell JA (1995) Central endogenous opioid inhibition of supraoptic oxytocin neurons in pregnant rats. J Neurosci 15:5049-5057.

Douglas AJ, Bicknell RJ, Leng G, Russell JA, Meddle SL (2002) $\beta$-Endorphin cells in the arcuate nucleus: projections to the supraoptic nucleus and changes in expression during pregnancy and parturition. J Neuroendocrinol 14:768-777.

Drago F, Pedersen CA, Caldwell JD, Prange Jr AJ (1986) Oxytocin potently enhances novelty-induced grooming behavior in the rat. Brain Res 368:287-295.

Fiorillo JT, Williams JT (1998) Glutamate mediates an inhibitory postsynaptic potential in dopamine neurons. Nature 394:78-82.

Fong TM, Van der Ploeg LHT (2000) A melanocortin agonist reduces neuronal firing rate in rat hypothalamic slices. Neurosci Lett 283:5-8.

Freund-Mercier MJ, Richard PH (1984) Electrophysiological evidence for facilitatory control of oxytocin neurones by oxytocin during suckling in the rat. J Physiol (Lond) 352:447-466.

Giovannelli LP, Shiromani PJ, Jirikowski GF, Bloom FE (1990) Oxytocin neurons in the rat hypothalamus exhibit c-fos immunoreactivity upon osmotic stress. Brain Res 531:299-303.

Gouzenes L, Desarmenien M, Hussy N, Richard PH, Moos FC (1998) Vasopressin regularizes the phasic firing pattern of rat hypothalamic magnocellular vasopressin neurons. J Neurosci 18:1879-1885.

Hamamura M, Leng G, Emson PC, Kiyama H (1991) Electrical activation and c-fos mRNA expression in rat neurosecretory neurones after systemic administration of cholecystokinin. J Physiol (Lond) 444:51-63.

Higuchi T, Tadokoro Y, Honda K, Negoro H (1986) Detailed analysis of blood oxytocin levels during suckling and parturition in the rat. J Endocrinol 110:251-256.

Hoffman GE, Lyo D (2002) Anatomical markers of activity in neuroendocrine systems: are we all "Fos-ed out?" J Neuroendocrinol 14:259-268.

Hoffman GE, Smith MS, Verbalis JG (1993) c-Fos and related immediate early gene products as markers of activity in neuroendocrine systems. Front Neuroendocrinol 14:173-213.

Lambert RC, Dayanithi G, Moss FC, Richard PH (1994) A rise in the intracellular $\mathrm{Ca}^{2+}$ concentration of isolated rat supraoptic cells in response to oxytocin. J Physiol (Lond) 478:275-288.

Leng G, Dyball REJ (1991) Functional identification of magnocellular neuroendocrine neurons. In: Neuroendocrine research methods (Greenstein, B, ed), pp 769-791. London: Harwood Academic.

Leng G, Yamashita H, Dyball RE, Bunting R (1988) Electrophysiological evidence for a projection from the arcuate nucleus to the supraoptic nucleus. Neurosci Lett 89:146-151.

Leng G, Way S, Dyball REJ (1991) Identification of oxytocin cells in the rat supraoptic nucleus by their response to cholecystokinin injection. Neurosci Lett 122:159-162.

Leng G, Brown CH, Russell JA (1999) Physiological pathways regulating the activity of magnocellular neurosecretory cells. Prog Neurobiol 57:625-655.

Luckman SM, Dyball RE, Leng G (1994) Induction of $c$-fos expression in hypothalamic magnocellular neurons requires synaptic activation and not simply increased spike activity. J Neurosci 14:4825-4830. 
Ludwig M (1998) Dendritic release of vasopressin and oxytocin. J Neuroendocrinol 10:881-895.

Ludwig M, Leng G (1997) Autoinhibition of supraoptic nucleus vasopressin neurons in vivo: a combined retrodialysis/electrophysiological study in rats. Eur J Neurosci 9:2532-2540.

Ludwig M, Leng G (2000) GABAergic projection from the arcuate nucleus to the supraoptic nucleus in the rat. Neurosci Lett 281:195-197.

Ludwig M, Sabatier N, Bull PM, Landgraf R, Dayanithi G, Leng G (2002) Intracellular calcium stores regulate activity-dependent neuropeptide secretion from dendrites. Nature 418:85-89.

McCarthy MM, Altemus M (1997) Central nervous system actions of oxytocin and modulation of behavior in humans. Mol Med Today 3:269-275.

Morgan JI, Curran T (1988) Calcium as a modulator of the immediate-early gene cascade in neurons. Cell Calcium 9:303-311.

Mountjoy KG, Mortrud MT, Low MJ, Simerly RB, Cone RD (1994) Localization of the melanocortin-4 receptor (MC4-R) in neuroendocrine and autonomic control circuits in the brain. Mol Endocrinol 8:1298-1308.

Mountjoy KG, Kong PL, Taylor JA, Willard DH, Wilkison WO (2001) Melanocortin receptor-mediated mobilization of intracellular free calcium in HEK293 cells. Physiol Genomics 5:11-19.

O'Donohue TL, Dorsa DM (1982) The opiomelanotropinergic neuronal and endocrine systems. Peptides 3:353-395.

O'Donohue TL, Jacobowitz DM (1980) Studies of $\alpha$-MSH-containing nerves in the brain. Prog Biochem Pharmacol 16:69-83.

Olszewski PK, Wirth MM, Shaw TJ, Grace MK, Billington CJ, Giraudo SQ, Levine AS (2001) Role of $\alpha$-MSH in the regulation of consummatory behavior: immunohistochemical evidence. Am J Physiol Regul Integr Comp Physiol 281:R673-R680.

Renaud LP, Tang M, McCann MJ, Stricker EM, Verbalis JG (1987) Cholecystokinin and gastric distension activate oxytocinergic cells in rat hypothalamus. Am J Physiol 253:R661-R665.

Sabatier N, Caquineau C, Douglas AJ, Leng G (2003) Oxytocin released from magnocellular dendrites: a potential modulator of $\alpha$-melanocyte stimulating hormone behavioural actions. Ann NY Acad Sci 994:218-224.

Sagar SM, Sharp FR (1993) Early response genes as markers of neuronal activity and growth factor action. Adv Neurol 59:273-284.

Sawchenko PE, Swanson LW, Joseph SA (1982) The distribution and cells of origin of ACTH(1-39)-stained varicosities in the paraventricular and supraoptic nuclei. Brain Res 232:365-374.

Sgambato V, Abo V, Rogard M, Besson MJ, Deniau JM (1997) Effect of electrical stimulation of the cerebral cortex on the expression of the Fos protein in the basal ganglia. Neuroscience 81:93-112.

Thiele TE, van Dijk G, Yagaloff KA, Fisher SL, Schwartz M, Burn P, Seeley RJ (1998) Central infusion of melanocortin agonist MTII in rats: assessment of c-Fos expression and taste aversion. Am J Physiol 274:R248-R254.

Verbalis GJ, McCann MJ, McHale CM, Stricker EM (1986) Oxytocin secretion in response to cholecystokinin and food: differentiation of nausea from satiety. Science 232:1417-1419.

Vergoni AN, Bertolini A (2001) Role of melanocortins in the central control of feeding. Eur J Pharmacol 405:25-32.

Watson SJ, Akil H (1980) $\alpha$-MSH in rat brain: occurrence within and outside of $\beta$-endorphin neurons. Brain Res 182:217-223. 